\title{
The value of contrast-enhanced ultrasound enhancement patterns for the diagnosis of sentinel lymph node status in breast cancer: systematic review and meta-analysis
}

\author{
Zihan Niu^, Mengsu Xiao^, Li Ma^, Jing Qin^, Wenbo Li^, Jing Zhang^, Qingli Zhu^, Yuxin Jiang^ \\ Department of Ultrasound, Peking Union Medical College Hospital, Chinese Academy of Medical Sciences and Peking Union Medical College, \\ Beijing, China
}

Contributions: (I) Conception and design: Q Zhu, J Zhang, Z Niu; (II) Administrative support: Y Jiang, Q Zhu; (III) Provision of study materials or patients: Z Niu, M Xiao, L Ma; (IV) Collection and assembly of data: Z Niu, M Xiao, L Ma; (V) Data analysis and interpretation: Z Niu, M Xiao, L Ma, J Qin, W Li; (VI) Manuscript writing: All authors; (VII) Final approval of manuscript: All authors.

Correspondence to: Qingli Zhu; Yuxin Jiang. No. 1 Shuaifuyuan, Dongdan, Beijing 100730, China. Email: zqlpumch@126.com; yuxinjiangxh@163.com.

Background: The sentinel lymph node (SLN) can represent the metastasis status of axillary lymph nodes
and is a prognostic factor of breast cancer. Preoperative imaging provides information for axillary surgery
decision-making, and this meta-analysis evaluated the diagnostic value of contrast-enhanced ultrasound
(CEUS) for SLN status in breast cancer patients.
Methods: The PubMed, Embase, Medline, Google Scholar, Clinical Trails gov. and Cochrane Library
databases were searched from inception until 31 March 2020. Two review authors independently screened
and selected the relevant studies and extracted data, and the assessment of the methodological quality of
studies was according to the QUADAS-2 tool. The diagnostic value of CEUS was assessed by calculating
the pooled sensitivity, specificity, area under the curve, positive likelihood ratio, negative likelihood ratio,
and diagnostic odds ratio, and a summary receiver operating characteristic curve and hierarchical modeling
method was used to conduct the meta-analysis. Results: Five studies with 771 breast cancer patients were included, and the results showed CEUS could provide additional information for SLN preoperative diagnosis. A homogeneous or uniform enhancement pattern suggested a benign lymph node, and a heterogeneous, no pattern, or weak enhancement pattern suggested a node was malignant, demonstrating high sensitivity of 0.960 (95\% CI: $0.856,0.989)$ and moderate specificity of $0.807(0.581,0.926)$. The pooled positive likelihood ratio, negative likelihood ratio, and diagnostic odds ratio were $4.987(2.104,11.822)$ and $0.049(0.014,0.168)$, and $101.294(31.202,328.837)$, respectively.

Conclusions: A homogeneous enhancement pattern was highly suggestive of benign lymph nodes with high sensitivity. CEUS could effectively identify the SLN, and facilitate the diagnosis of its metastatic status.

Registration Number: PROSPERO protocol CRD42020176828.

Keywords: Contrast-enhanced ultrasound (CEUS); breast cancer; sentinel lymph node (SLN); meta-analysis

Submitted Apr 19, 2021. Accepted for publication Aug 20, 2021.

doi: 10.21037/qims-21-416

View this article at: https://dx.doi.org/10.21037/qims-21-416

\footnotetext{
^ ORCID: Qingli Zhu, 0000-0002-0618-2381; Yuxin Jiang, 0000-0002-0154-3686; Zihan Niu, 0000-0003-1390-2743; Mengsu Xiao, 00000003-1631-3696; Li Ma, 0000-0001-5380-0499; Jing Qin, 0000-0002-6029-7673; Wenbo Li, 0000-0003-4016-7158; Jing Zhang, 00000001-6910-6055.
} 


\section{Introduction}

The metastatic status of the axillary lymph nodes is one of the most important prognostic factors for determining clinical outcomes in breast cancer patients $(1,2)$, and the sentinel lymph node (SLN), as the first lymph node receiving breast lymphatic drainage, can represent axillary lymph node status. SLN biopsy is considered a pivotal development in breast cancer treatment and has drawn more attention after the publication of the American College of Surgeons Oncology Group (ACOSOG) Z0011 trial $(3,4)$.

At present, the SLN can be displayed by blue dye, indocyanine green, or nuclide during surgery, and qualitative diagnosis can be made in combination with biopsy $(5,6)$. However, establishing a diagnosis before surgery might omit the need for biopsy and lymph node clearance and would help to provide information for axillary management.

Conventional preoperative imaging methods can provide diagnostic information for axillary lymph nodes but are not ideal for the localization and qualitative assessment of the SLN (7). With the rapid development of ultrasound, the SLN can be identified preoperatively by percutaneous contrast-enhanced ultrasound (CEUS) (8-10), as the contrast medium accumulates in the SLN and can be identified by tracing the lymph channels in which it also accumulates. Many studies have confirmed that the SLN located by CEUS is the same SLN located by blue dye during surgery (11-15), and previous studies showed the SLN could be diagnosed by CEUS-guided core biopsy $(16,17)$. However, there is doubt over whether a single biopsy-proven metastatic node can preclude SLN biopsy in otherwise eligible women. In recent years, research has demonstrated that CEUS can locate the SLN and further differentiate SLN status through its enhancement pattern $(11,18-21)$. However, there is still some discrepancy between different studies on the diagnostic performance of CEUS.

While a previous meta-analysis by Zhang evaluated the value of CEUS for axillary lymph nodes in breast cancer, including the percutaneous or intravenous administration route, it is difficult to determine the first lymph node through this intravenous injection method, and differential diagnosis of the index lymph nodes could not be confirmed as the SLN (22). In addition, the CEUS enhancement patterns for the SLN lacked a clear definition using this method. Therefore, we conducted a meta-analysis to evaluate the diagnostic value of CEUS enhancement patterns for SLNs identified by the percutaneous route. By strictly filtering studies, the enhancement pattern of CEUS and the criteria for evaluating SLN status were analyzed, and recent literature was updated to supplement the research data.

We present the following article in accordance with the PRISMA reporting checklist (available at https://dx.doi. org/10.21037/qims-21-416).

\section{Methods}

This meta-analysis was conducted according to the Preferred Reporting Items for Systematic Reviews and Meta-Analysis (PRISMA) of Diagnostic Tests Accuracy guidelines (23). The protocol of this systematic review was registered on the PROSPERO registry before starting the literature search (PROSPERO protocol CRD42020176828).

\section{Literature search}

A comprehensive search of the PubMed, EMBASE, MEDLINE, Google Scholar, Clinical Trails gov. and Cochrane Library databases was performed from the inception of each database to 31 March 2020 with English language restrictions. Preliminary keywords, Medical Subject Headings (MeSH) terms, and entry terms, including breast neoplasms, sentinel lymph node, ultrasonography, contrast media, and diagnosis, were combined to generate lists of studies, and the search strategy is shown in the supplementary file. No restrictions about the date of publication were applied for our research.

\section{Selection criteria}

Full-text articles were thoroughly assessed according to the following eligibility criteria: (I) population: patients diagnosed with breast cancer; (II) intervention/exposure: CEUS for SLN was performed, and the enhancement patterns of each case were clearly described; (III) comparison: the pathological results of SLN during operation; (IV) outcome: the diagnostic accuracy of SLNs by preoperative CEUS was assessed, and the data allowed the construction of a $2 \times 2$ table for calculating the diagnostic accuracy of preoperative CEUS, including true positive (TP), false positive (FP), false negative ( $\mathrm{FN}$ ), and true negative $(\mathrm{TN})$ results. Publications were excluded if they 
met any of the following criteria: (I) articles investigating issues not directly relevant to this study; (II) studies that included patients who had previously undergone radio-/ chemo therapy; (III) insufficient data: data only included the identification rate or the diagnostic value of CEUS-guided core biopsy, and did not include the enhancement pattern and corresponding pathological findings; (IV) sample size $<20$ patients; (V) data included in subsequent articles or duplicate reports, in which case the article with the most recent publication date or with the largest sample size was included. We excluded publications of meetings abstracts, reviews, case reports, and editorials. In this study, two independent reviewers screened the titles, abstracts, and full-text of the articles, and disagreements were resolved by consensus.

\section{Data extraction and quality assessment}

The extracted data included basic research information (first author, country, number of patients, year of publication); patient characteristics (age, preoperative axillary lymph node staging method); intervention information (contrast agent, injection route); diagnostic criteria (enhancement pattern, diagnostic threshold, other SLN comparative examination methods); and diagnostic results (SLN detection rate). Two independent reviewers assessed the risk of bias in the included studies according to the Quality Assessment of Diagnostic Accuracy Studies-2 tool (QUADAS-2) (24). Differences were resolved through discussion.

\section{Data analysis}

The classic biostatistical measurements of diagnostic accuracy were evaluated: (I) diagnostic measurements: sensitivity, specificity, diagnostic odds ratio, area under the curve (AUC); and (II) predictive measurements: positive and negative likelihood ratios $(25,26)$. All measurements were calculated based on a $2 \times 2$ contingency table of diagnostic performance. When the diagnostic odds ratio was calculated, 0.5 was added to all cell values as a correction if 0 counts occurred in any of the cells in the table. The sensitivity, specificity, diagnostic odds ratio, positive likelihood ratio, negative likelihood ratio, and AUC were calculated as meta-analytic pooled data estimates with $95 \%$ confidence intervals (95\% CIs) using the DerSimonianLiard random effect model (27). The AUC ranged from 0 to 1 and was classified as poor $(<0.5)$, low $(0.5 \leq \mathrm{AUC}<0.7)$, moderate $(0.7 \leq \mathrm{AUC}<0.9)$, or high $(0.9 \leq \mathrm{AUC}=1)(28)$. A summary receiver operating characteristic (SROC) curve and a hierarchical receiver-operating characteristic summary (HSROC) were also performed.

\section{Evaluation of beterogeneity, meta-regression, and publication bias}

Heterogeneity was assessed between studies using Cochran's Q-statistic and the $\mathrm{I}^{2}$ test. The random-effect model was conducted if the $\mathrm{Q}$ test showed a $\mathrm{P}<0.05$ or $\mathrm{I}^{2}>50 \%$ (29); otherwise, the fixed-effects model was used. To examine the potential sources of heterogeneity observed in the meta-analysis, subgroup analysis was performed using the following covariates: (I) sample size, (II) unit of study, (III) contrast agents, and (IV) axillary lymph node staging method. Additionally, a sensitivity analysis was performed to evaluate the influence of single studies on the overall estimates. The publication bias was investigated using Egger's linear regression (30).

Meta-analysis was performed using Meta-Disc version 1.4 (Meta-disc, Unit of Clinical Biostatistics of Ramony Cajal Hospital, Madrid, Spain), Stata version 14.0 (Stata Corp LP, College Station, TX, USA), and Review Manager Version 5.3 (The Cochrane Collaboration, Software Update, Oxford, UK).

\section{Results}

\section{Included studies and quality assessment}

A total of 2,180 studies were identified in search of the databases, and 27 additional manuscripts were obtained through a review of relevant literature or references. After excluding duplicated articles, the remaining 1,766 articles were obtained. Of these, 597 articles, including reviews, case reports, guidelines, and animal experiments, were excluded, while 1,070 were excluded after the title and abstract analysis were read. A further 93 studies were excluded by reading the full text, and one study was excluded because of data overlapping with a full-text study (31). Finally, five studies were included in this meta-analysis $(11,18-21)$. The flow chart to this process is shown in Figure 1.

Of the included studies, a positive case was defined when metastatic nodes were confirmed in SLN biopsy and/or axillary lymph node dissection, and a negative case when no metastasis was found in SLN biopsy or whole axillary nodes dissection. Four studies used SonoVue (Bracco Imaging, Milan, Italy) subcutaneous injection, while one 


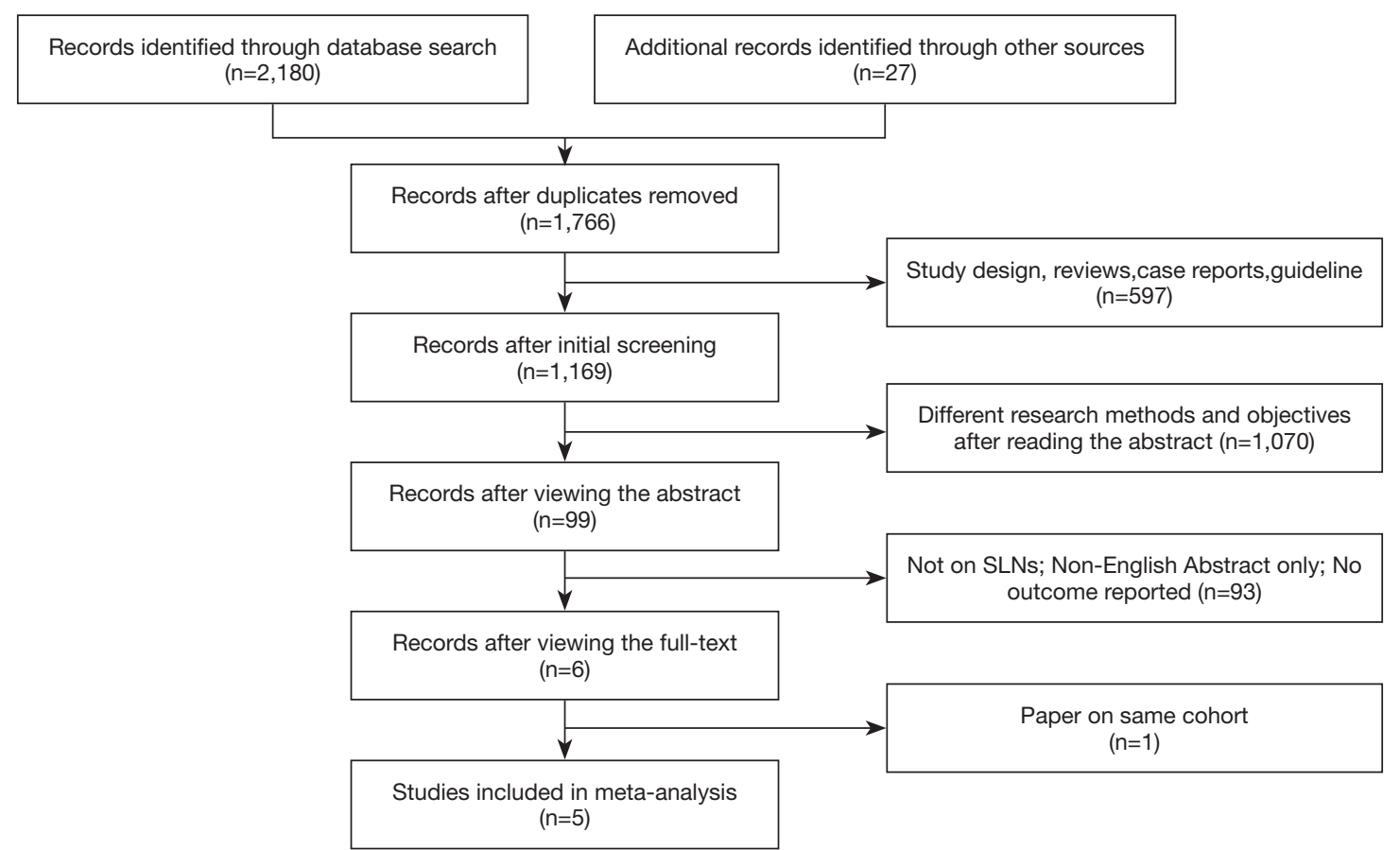

Figure 1 Flow chart of literature search and study selection. Five studies were included in this meta-analysis.

Table 1 Characteristics of individual studies included in the meta-analysis

\begin{tabular}{|c|c|c|c|c|c|c|c|c|c|c|c|c|c|c|}
\hline \multicolumn{2}{|c|}{ No Author } & $\begin{array}{l}\text { Year } \\
2015\end{array}$ & $\begin{array}{l}\text { Country } \\
\text { China }\end{array}$ & $\begin{array}{c}\begin{array}{c}\text { Unit } \\
\text { of } \\
\text { study }\end{array} \\
P\end{array}$ & $\begin{array}{c}\begin{array}{c}\text { Patient } \\
\text { total }\end{array} \\
101\end{array}$ & $\begin{array}{r}\text { SLN } \\
\text { total } \\
115\end{array}$ & $\begin{array}{l}\text { To } \\
98\end{array}$ & $\begin{array}{c}\begin{array}{c}\text { Detected } \\
\text { rate }\end{array} \\
97.03\end{array}$ & $\begin{array}{c}\begin{array}{c}\text { Age } \\
\text { (years) }\end{array} \\
54 \\
{[22-82]}\end{array}$ & $\begin{array}{c}\begin{array}{c}\text { Preoperative } \\
\text { axillary lymph } \\
\text { node staging }\end{array} \\
\text { NA }\end{array}$ & $\begin{array}{c}\text { Administration } \\
\text { route }\end{array}$ & $\begin{array}{c}\text { Instrument } \\
\text { GE }\end{array}$ & $\begin{array}{c}\begin{array}{c}\text { Contrast } \\
\text { agent }\end{array} \\
\text { Sonovue }\end{array}$ & $\begin{array}{l}\text { Pathological } \\
\text { examination }\end{array}$ \\
\hline 2 & $\begin{array}{l}\text { Matsuzawa } \\
\mathrm{F}\end{array}$ & 2015 & Japan & $\mathrm{P}$ & 32 & 32 & 32 & 100 & $\begin{array}{c}60 \\
{[32-86]}\end{array}$ & $\begin{array}{c}\text { Clinical } \\
(+/-, 2 / 30)\end{array}$ & $\begin{array}{c}\text { Intravenous + } \\
\text { intradermal }\end{array}$ & Aplio & Sonazoid & $\begin{array}{l}\text { ICG/CECT + } \\
\text { SLN biopsy }\end{array}$ \\
\hline 4 & Li J & 2019 & China & SLN & 453 & 765 & 765 & 98.2 & $\begin{array}{c}49 \\
{[28-72]}\end{array}$ & Clinical/US (-) & intradermal & Philip & Sonovue & $\begin{array}{c}\text { Blue/carbon dye } \\
+ \text { SLN biopsy }\end{array}$ \\
\hline 5 & Liu J & 2019 & China & SLN & 75 & 116 & 116 & 94.67 & $\begin{array}{c}49 \\
{[31-71]}\end{array}$ & Clinical (-) & intradermal & Philip & Sonovue & $\begin{array}{l}\text { Blue dye + } \\
\text { SLN biopsy }\end{array}$ \\
\hline
\end{tabular}

SLN, sentinel lymph node; US, ultrasound; ICG, indocyanine green; CECT, contrast enhanced computed tomography; P, patient; SLN, sentinel lymph node; NA, not applicable.

study used Sonazoid (NA, Tokyo, Japan) as the contrast agent. For the Sonovue group, the patterns of each study were slightly different and were divided into three or four enhancement patterns. According to the enhancement of the SLN, a homogeneous enhancement pattern was defined as benign, and other types, such as uneven enhancement and nonenhancement patterns, were defined as malignant. For the Sonazoid group, SLNs were located through subcutaneous injection, and qualitative diagnostics were evaluated through intravenous injection by lymphatic hilum microflow perfusion. All studies adopted SLN biopsy as the gold standard, and the main information is summarized in Table 1. The enhancement pattern and diagnostic criteria of each study are shown in Table 2.

The quality assessment using the QUADAS-2 tool is shown in Figure 2. The results showed three studies were 
Table 2 Enhancement model and diagnostic criteria of individual studies included in the meta-analysis

\begin{tabular}{|c|c|c|c|c|c|c|c|c|}
\hline Author & \multicolumn{2}{|c|}{ The assessment criteria: enhancement of CEUS (+/-) } & $\begin{array}{l}\text { Pathology } \\
(+/-)\end{array}$ & TP & FP & $\mathrm{FN}$ & $\mathrm{TN}$ & To \\
\hline Xie F & $\begin{array}{l}\text { Obvious and homogeneous } \\
\qquad(6 / 56)\end{array}$ & $\begin{array}{l}\text { Obvious with hypo- or non-perfusion (23/7); } \\
\text { Weak or non-enhanced ( } 4 / 2)\end{array}$ & $33 / 65$ & 27 & 9 & 6 & 56 & 98 \\
\hline Matsuzawa F & $\begin{array}{l}\text { Flows from a single vessel of } \\
\text { the hilum }(2 / 20)\end{array}$ & $\begin{array}{l}\text { Flows from multiple microvessels except for hilum } \\
\text { (more than two vessels) }(9 / 1)\end{array}$ & $11 / 21$ & 9 & 1 & 2 & 20 & 32 \\
\hline Li J & Homogeneous (9/443) & $\begin{array}{l}\text { Inhomogeneous (228/35); } \\
\text { Non-enhanced (46/4) }\end{array}$ & $283 / 482$ & 274 & 39 & 9 & 443 & 765 \\
\hline Liu J & Overall uniform (1/32) & $\begin{array}{l}\text { Uneven (mixture of high and low) }(29 / 24) \text {; } \\
\text { Annular, low or no center enhancement (10/6); } \\
\text { No or weak enhancement (11/3) }\end{array}$ & $51 / 65$ & 50 & 33 & 1 & 32 & 116 \\
\hline
\end{tabular}

CEUS, contrast-enhanced ultrasound; +/-, the ratio of positive to negative axillary lymph node; TP, true positive; FP, false positive; FN, false negative; TN, true negative; To, total.
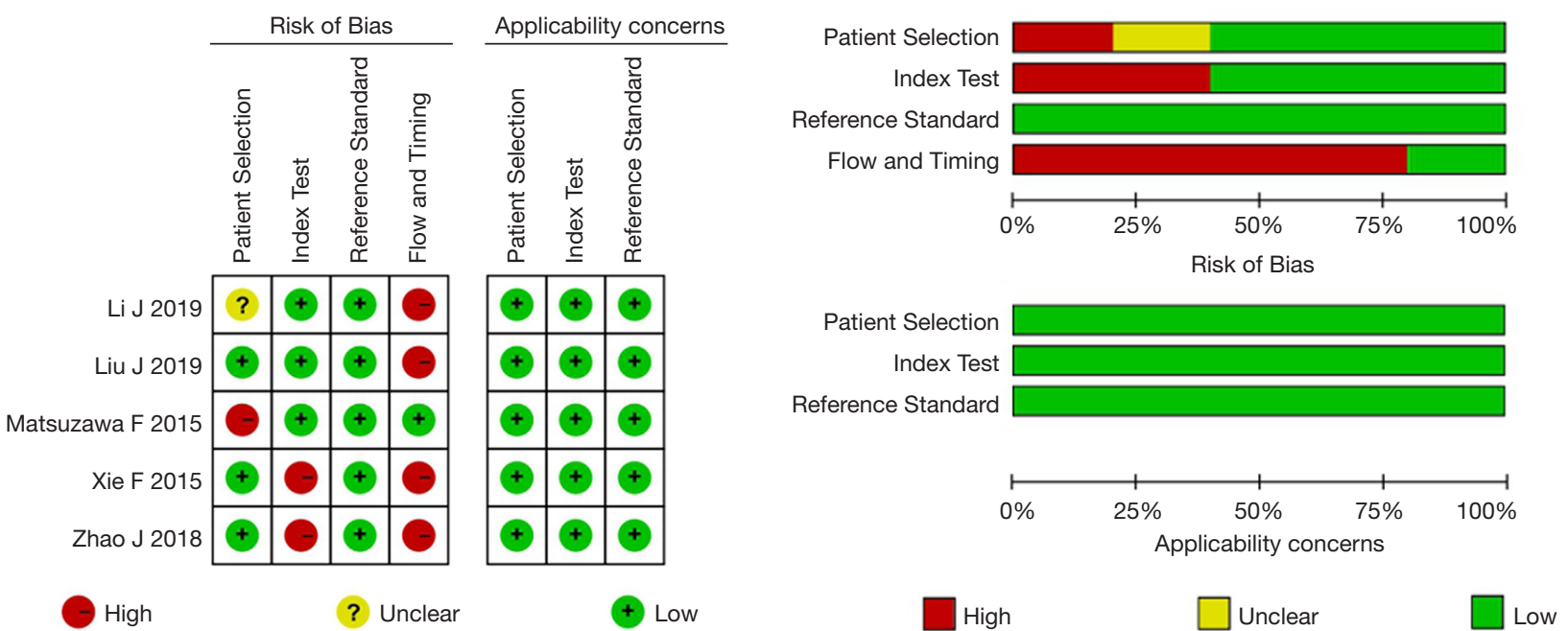

Figure 2 Quadas-2 results of five studies. (A) Risk of bias and applicability concerns summary: review authors' judgment about each domain for each included study; (B) each domain is presented as percentages across the included studies.

of good quality and two studies were of fair quality, while in four studies, due to technical limitations, the SLNs in $94.67-100 \%$ of patients were identified by CEUS, so the diagnostic accuracy of all enrolled patients could not be analyzed, and the quality of flow and timing was evaluated as high risk. In addition, two studies did not set the diagnostic threshold for CEUS in advance, causing the risk of bias. All studies showed high applicability.

\section{Differential diagnosis between benign and malignant SLNs}

Meta-analysis results of the five studies using the random effect model are summarized in Table 3. CEUS had a sensitivity range from 0.82 to 1.00 and a specificity range from 0.49 to 0.95 for the qualitative diagnosis of SLNs. Significant heterogeneity was found in sensitivity $\left(\mathrm{I}^{2}=76.1 \%\right)$, specificity $\left(\mathrm{I}^{2}=96.8 \%\right)$, positive likelihood 
Table 3 Meta-analysis of diagnostic accuracy under the HSROC model

\begin{tabular}{lccc}
\hline & Pooled value & Standard error & $95 \% \mathrm{Cl}$ \\
\hline Sensitivity & 0.960 & 0.027 & $0.856-0.989$ \\
Specificity & 0.807 & 0.087 & $0.581-0.926$ \\
Diagnostic odds ratio & 101.294 & 60.856 & $31.202-328.837$ \\
Positive likelihood ratio & 4.987 & 2.196 & $2.104-11.822$ \\
Negative likelihood ratio & 0.049 & 0.031 & $0.014-0.168$ \\
\hline
\end{tabular}

$\mathrm{Cl}$, confidence interval; HSROC, hierarchical summary receiver operating characteristics.

ratio $\left(\mathrm{I}^{2}=97.9 \%\right)$, and negative likelihood ratio $\left(\mathrm{I}^{2}=79.3 \%\right)$ (Figure 3). The SROC analysis for the studies yielded an overall weighted area under the curve of 0.9588 , and the $\mathrm{Q}^{*}$ index was 0.9028 (Figure 4). An HSROC model was also performed to pool the diagnostic parameters, which showed the pooled sensitivity of studies was 0.960 (95\% CI: 0.856 0.989 ) and the pooled specificity was 0.807 (95\% CI: $0.581-$ 0.926). The pooled diagnostic odds ratio was 101.294 (95\% CI: 31.202-328.837), and the pooled positive and negative likelihood ratio values were 4.987 (95\% CI: 2.104-11.822) and 0.049 (95\% CI: 0.014-0.168), respectively (Table 3, Figure 5). The sensitivity, specificity, diagnostic odds ratio, positive likelihood ratio, and negative likelihood ratio, and the SROC and HSROC plots are presented in Figures 3-5, respectively.

\section{Diagnostic accuracy of CEUS in subgroup analysis}

The factors that may lead to heterogeneity between studies were further explored through subgroup analysis, including sample size ( $<100, \geq 100$ patients), axillary lymph node stage (clinical positive or not applicable, negative), unity of study (patient, SLN), and contrast agents (SonoVue, Sonazoid). Meta-regression results showed that the choice of contrast agent $(\mathrm{P}=0.02)$ affected the sensitivity heterogeneity, while the unit of study $(\mathrm{P}=0.06)$, stage of axillary lymph node $(\mathrm{P}=0.06)$, and sample size $(\mathrm{P}=0.09)$ slightly affected sensitivity heterogeneity. Contrast agent $(\mathrm{P}=0.61)$, sample size $(\mathrm{P}=0.58)$, stage of axillary lymph node $(\mathrm{P}=0.18)$, and unit of study $(\mathrm{P}=0.18)$ were not contributors to specificity heterogeneity (Figure 6, Table 4).

Three studies involved SLNs as the unit of study (19-21), and the AUC was 0.973. There was no heterogeneity in the sensitivity between studies, and the specificity was still highly heterogeneous, which may be due to the large sample size of the Li et al. study (20). Two studies set patients as the unit of study, and the combined sensitivity and specificity were 0.818 and 0.884 , respectively.

Diagnostic accuracy was analyzed separately for the different contrast agents used for CEUS. The diagnostic criteria of the four studies were able to diagnose SLN by the enhanced pattern using SonoVue contrast, with a homogeneous enhancement pattern defined as benign and other patterns defined as malignant (11,19-21). The combined sensitivity, specificity, positive likelihood ratio, negative likelihood ratio, and diagnostic odds ratio were $0.960,0.820,4.060,0.061$, and 84.133 , respectively, and the AUC was 0.958 . The diagnostic sensitivity was better than specificity, and CEUS had a high diagnostic efficiency for evaluating SLN. Compared with SonoVue, Sonazoid had a higher specificity but a lower sensitivity.

There was no change in the heterogeneity of sensitivity and specificity between SLN with different clinical diagnoses. The sensitivity, specificity, positive likelihood ratio, negative likelihood ratio, and diagnostic odds ratio for SLN with negative clinical palpation could reach $0.973,0.816,3.612,0.035$, and 149.89 , respectively, which demonstrated good performance for CEUS.

\section{Influence analysis of CEUS in each group}

The influence analysis is shown in Figure 7. Every single study was excluded in turn, and the overall summary DORs were calculated for the remaining studies. The predicted value of the study by Li et al. deviated from the 95\% CIs (20), and may be because it contained a large sample size, which accounted for $58.75 \%(453 / 771)$ of the five studies, and significantly affected the final result.

\section{Publication bias}

Egger's test was performed on each study and is shown 
A

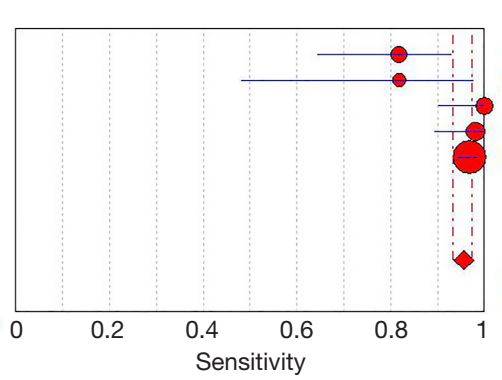

B

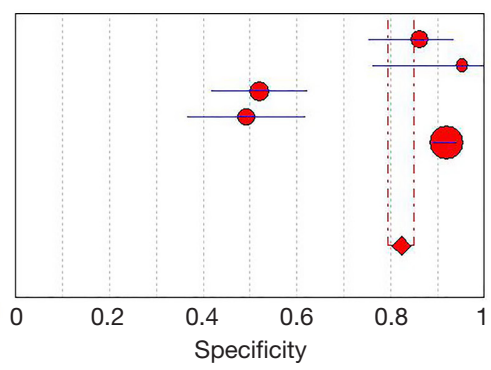

C

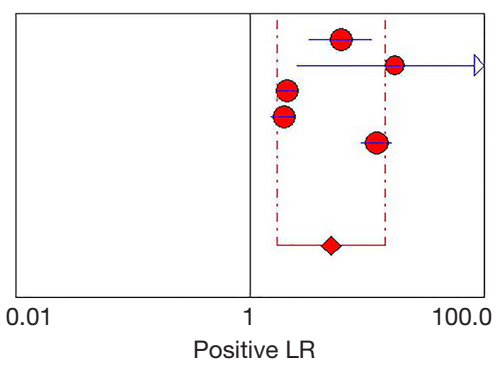

$\mathrm{D}$

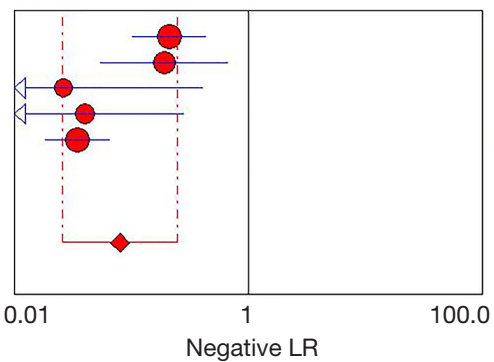

E

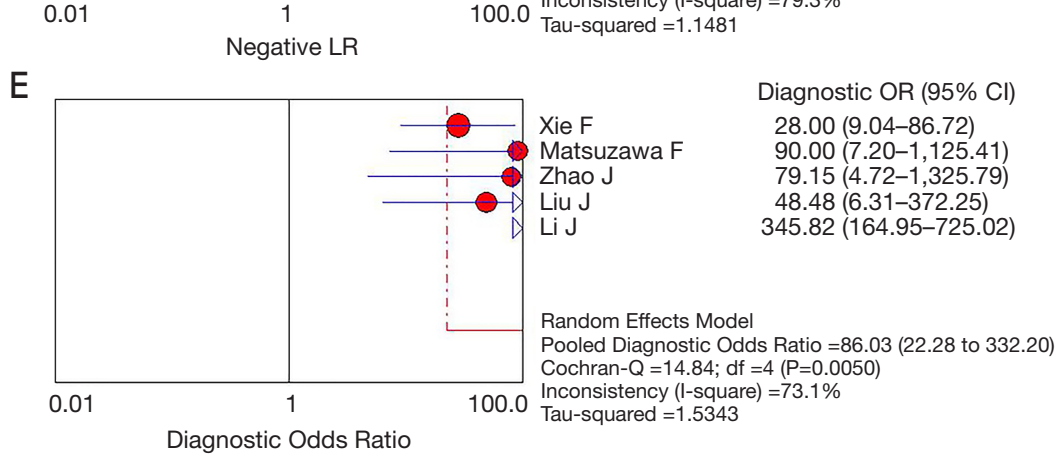

Sensitivity $(95 \% \mathrm{Cl})$

$0.82(0.65-0.93)$

$0.82(0.48-0.98)$

$1.00(0.90-1.00)$

$0.98(0.90-1.00)$

$0.97(0.94-0.99)$

Pooled Sensitivity $=0.96$ (0.93 to 0.97$)$

Inconsistency (I-square) $=76.1 \%$

Specificity $(95 \% \mathrm{Cl})$

$0.86(0.75-0.93)$

$0.95(0.76-1.00)$

$0.52(0.42-0.62)$

$0.49(0.37-0.62)$

$0.92(0.89-0.94)$

Liu
Chi-square $=16.74 ; \mathrm{df}=4(\mathrm{P}=0.0022)$

Chi-square $=124.30 ; \mathrm{df}=4(\mathrm{P}=0.0000)$

Inconsistency (I-square) $=96.8 \%$

Positive LR (95\% CI)

$5.91(3.16-11.07)$

$17.18(2.49-118.72)$

$\begin{array}{lr}\text { Matsuzawa F } & 17.18(2.49-118.7 \\ \text { Zhao J } & 2.06(1.67-2.53) \\ \text { Liu J } & 1.93(1.52-2.46) \\ \text { Li J } & 11.97(8.85-16.18)\end{array}$

$\begin{array}{lr}\text { Matsuzawa F } & 17.18(2.49-118.7 \\ \text { Zhao J } & 2.06(1.67-2.53) \\ \text { Liu J } & 1.93(1.52-2.46) \\ \text { Li J } & 11.97(8.85-16.18\end{array}$

$\begin{array}{lr}\text { Matsuzawa F } & 17.18(2.49-118.72) \\ \text { Zhao J } & 2.06(1.67-2.53) \\ \text { Liu J } & 1.93(1.52-2.46) \\ \text { Li J } & 11.97(8.85-16.18)\end{array}$

Random Effects Model

Pooled Positive LR =4.89 (1.69 to 14.13)

Cochran $-\mathrm{Q}=186.16 ; \mathrm{df}=4(\mathrm{P}=0.0000)$

Inconsistency (I-square) $=97.9 \%$

Tau-squared $=1.3090$

$0.21(0.10-0.44)$

$0.19(0.05-0.67)$

$0.03(0.00-0.41)$

$0.04(0.01-0.28)$

$0.03(0.02-0.07)$

Random Effects Model

Pooled Negative LR $=0.08$ (0.03 to 0.24$)$

Cochran- $Q=19.28 ; d f=4(P=0.0007)$

Inconsistency (I-square) $=79.3 \%$

Tau-squared $=1.1481$

Figure 3 Forest plots of sensitivity (A), specificity (B), positive LR (C), negative LR (D), and diagnostic odds ratio (E) estimates of CEUS for SLN. Circles and lines represent point estimates and 95\% confidence intervals, respectively. Circled areas represent relative study sizes. LR, likelihood ratio; CEUS, contrast-enhanced ultrasound; SLN, sentinel lymph node. 


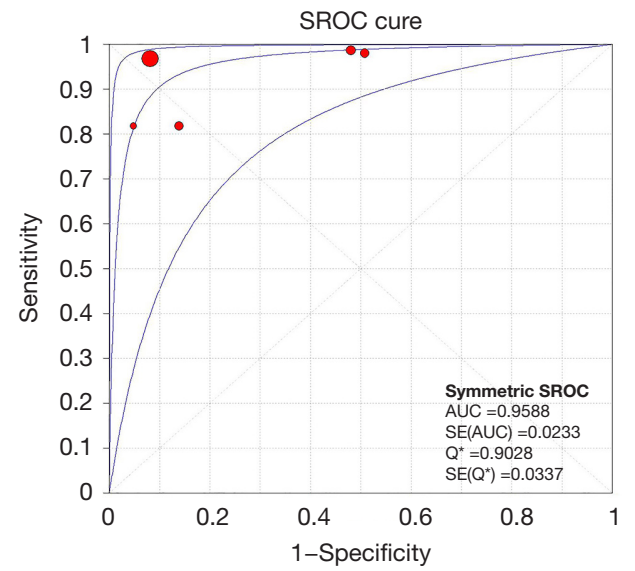

Figure 4 SROC curves for CEUS in the diagnosis of SLN. Solid circles represent the individual studies included in this metaanalysis. The curve shown is a regression line that summarizes the overall diagnostic accuracy. SE (AUC), standard error of the area under the curve; SROC, summary receiver operating characteristic; $\mathrm{Q}^{*}$, an index defined by the point on the SROC where the sensitivity and specificity are equal; SE $\left(Q^{*}\right), Q^{*}$ index standard error; CEUS, contrast-enhanced ultrasound; SLN, sentinel lymph node.

in Figure 8. The y-axis represents the standard normal deviation (SND), and the $\mathrm{x}$-axis represents the precision of the estimated effect. The regression line was drawn by weighting the sample size of each study. Egger's test was $\mathrm{P}>|\mathrm{t}|=0.816$ for the comprehensive analysis of the five articles, indicating there was no publication bias.

\section{Discussion}

According to the eighth edition of the American Joint Committee on Cancer Staging, the clinical categorization of an axillary lymph node includes clinical (palpation at physical examination) or imaging examination (32). A metaanalysis showed that for lymph nodes with a clinically negative diagnosis of breast cancer, the sensitivity and specificity of conventional ultrasound were $49-87 \%$ and $55-97 \%$, respectively (32). While pre-operative axillary ultrasound is the primary method for assessing axillary lymph node involvement, the application of a new method like elastography has the potential for assessing axillary metastasis (33-35). However, it is difficult to localize and qualitatively assess SLNs using this method. By using intradermal contrast injection, CEUS can accurately identify the initial LN and perform qualitative analysis by

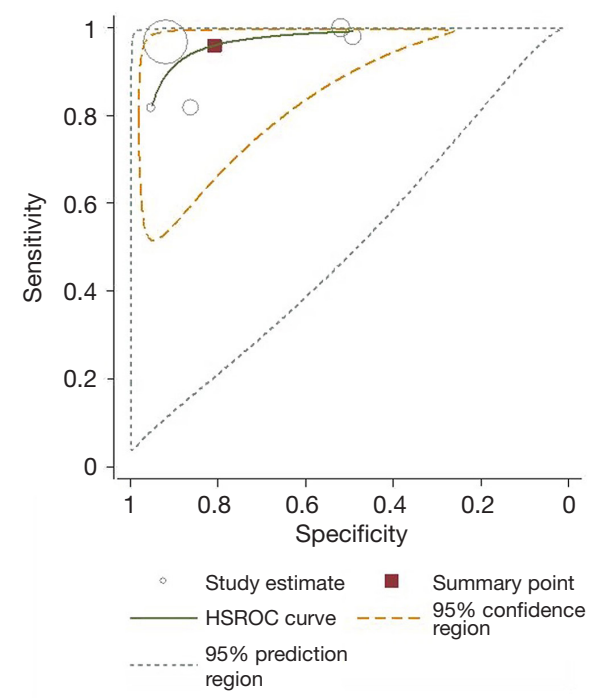

Figure 5 HSROC of CEUS for SLN metastasis diagnosis. HSROC, hierarchical summary receiver operating characteristics; CEUS, contrast-enhanced ultrasound; SLN, sentinel lymph node.

assessing the enhancement pattern, which further expands the research field of axillary lymph node evaluation and promotes the advancement of the preoperative imaging diagnosis of the SLN. This meta-analysis showed a correlation between the homogeneous CEUS enhancement pattern and benign SLNs, which provides information for selecting women with breast cancer into subgroups with disease-free axillary nodes.

In most cases, only one SLN is detected, although, in some patients, a second or even third node can be enhanced via the efferent lymphatic vessels of the first node. The rate of CEUS for SLN recognition and localization could reach $92-100 \%(11,15,18-21,36-38)$, which is comparable to traditional methods during operation. In our metaanalysis, the recognition rate of CEUS for SLNs was 94.67-100.00\%, which showed excellent performance and was consistent with the above research results.

While CEUS is mostly used in the localization of SLNs, many studies have found that the CEUS enhancement pattern has a certain diagnostic value for SLNs, which can be roughly divided into three patterns: I, homogeneous and uniform enhancement; II, uneven or heterogeneous enhancement; and III, weak or no enhancement. Pattern I indicates negative SLNs with high sensitivity and low 


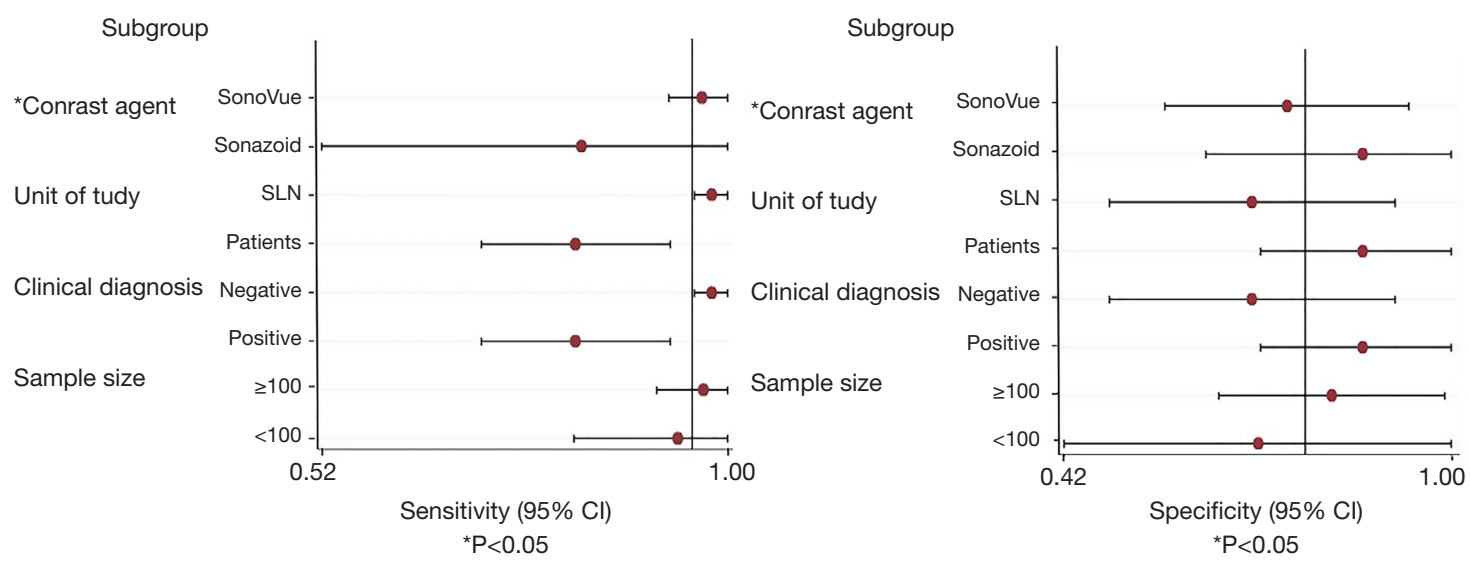

Figure 6 Univariable meta-regression in subgroup analyses and its $\mathrm{P}$ value.

Table 4 Summarized results of the meta-analysis

\begin{tabular}{|c|c|c|c|c|c|c|c|c|c|}
\hline Subgroup & Population & $\begin{array}{l}\text { Study } \\
\text { number }\end{array}$ & $\begin{array}{l}\text { Patients } \\
\text { total }\end{array}$ & AUC & Sensitivity & Specificity & $\begin{array}{c}\text { Positive } \\
\text { likelihood ratio }\end{array}$ & $\begin{array}{c}\text { Negative } \\
\text { likelihood ratio }\end{array}$ & $\begin{array}{l}\text { Diagnostic odds } \\
\text { ratio }\end{array}$ \\
\hline All combined & Overall & 5 & 771 & 0.939 & $\begin{array}{c}0.957 \\
(0.932-0.974)\end{array}$ & $\begin{array}{c}0.824 \\
(0.794-0.850)\end{array}$ & $\begin{array}{c}4.888 \\
(1.691-14.129)\end{array}$ & $\begin{array}{c}0.079 \\
(0.025-0.245)\end{array}$ & $\begin{array}{c}86.035 \\
(22.282-332.20)\end{array}$ \\
\hline Sample size & Number $\geq 100$ & 3 & 664 & 0.956 & $\begin{array}{c}0.957 \\
(0.931-0.976)\end{array}$ & $\begin{array}{c}0.853 \\
(0.823-0.879)\end{array}$ & $\begin{array}{c}5.241 \\
(1.016-27.026)\end{array}$ & $\begin{array}{c}0.067 \\
(0.013-0.345)\end{array}$ & $\begin{array}{c}97.104 \\
(13.747-685.92)\end{array}$ \\
\hline \multirow[t]{2}{*}{ Unit of study } & Patient & 2 & 133 & NA & $\begin{array}{c}0.818 \\
(0.673-0.918)\end{array}$ & $\begin{array}{c}0.884 \\
(0.797-0.943)\end{array}$ & $\begin{array}{c}6.856 \\
(3.254-14.445)\end{array}$ & $\begin{array}{c}0.206 \\
(0.109-0.387)\end{array}$ & $\begin{array}{c}34.023 \\
(12.124-95.476)\end{array}$ \\
\hline & SLN & 3 & 638 & 0.973 & $\begin{array}{c}0.973 \\
(0.951-0.987)\end{array}$ & $\begin{array}{c}0.816 \\
(0.783-0.845)\end{array}$ & $\begin{array}{c}3.612 \\
(0.931-14.004)\end{array}$ & $\begin{array}{c}0.035 \\
(0.019-0.063)\end{array}$ & $\begin{array}{c}149.89 \\
(33.999-660.77)\end{array}$ \\
\hline \multirow{2}{*}{$\begin{array}{l}\text { Preoperative } \\
\text { axillary lymph } \\
\text { node staging }\end{array}$} & Positive or NA & 2 & 133 & NA & $\begin{array}{c}0.818 \\
(0.673-0.918)\end{array}$ & $\begin{array}{c}0.884 \\
(0.797-0.943)\end{array}$ & $\begin{array}{c}6.856 \\
(3.254-14.445)\end{array}$ & $\begin{array}{c}0.206 \\
(0.109-0.387)\end{array}$ & $\begin{array}{c}34.023 \\
(12.124-95.476)\end{array}$ \\
\hline & Negative & 3 & 638 & 0.973 & $\begin{array}{c}0.973 \\
(0.951-0.987)\end{array}$ & $\begin{array}{c}0.816 \\
(0.783-0.845)\end{array}$ & $\begin{array}{c}3.612 \\
(0.931-14.004)\end{array}$ & $\begin{array}{c}0.035 \\
(0.019-0.063)\end{array}$ & $\begin{array}{c}149.89 \\
(33.999-660.77)\end{array}$ \\
\hline
\end{tabular}

SLN, sentinel lymph node; CEUS, contrast-enhanced ultrasound; NA, not Applicable; AUC, area under the curve; NA, not applicable.

negative likelihood ratio, while the value of pattern III to diagnose metastatic SLNs was indicated by high positive predictive values of $100 \%$ and $92 \%$ in studies by Zhao and Li, respectively $(19,20)$. In contrast, Pattern II has been shown to occur in both benign and malignant SLNs, and its value varied in different studies. The study conducted by Li et al. suggested that this pattern was prone to malignant
SLNs, and the ratio of malignant and benign SLNs was 228:35, while in the study of Zhao, benign SLNs were seen with a ratio of $29: 47$. We think the variability in the ratios of the true positive and negative cases between these studies might be caused by different inclusion criteria. In the study of $\mathrm{Li}$, patients with negative physical palpation and the axillary US were included, while in those of Zhao and Liu, 


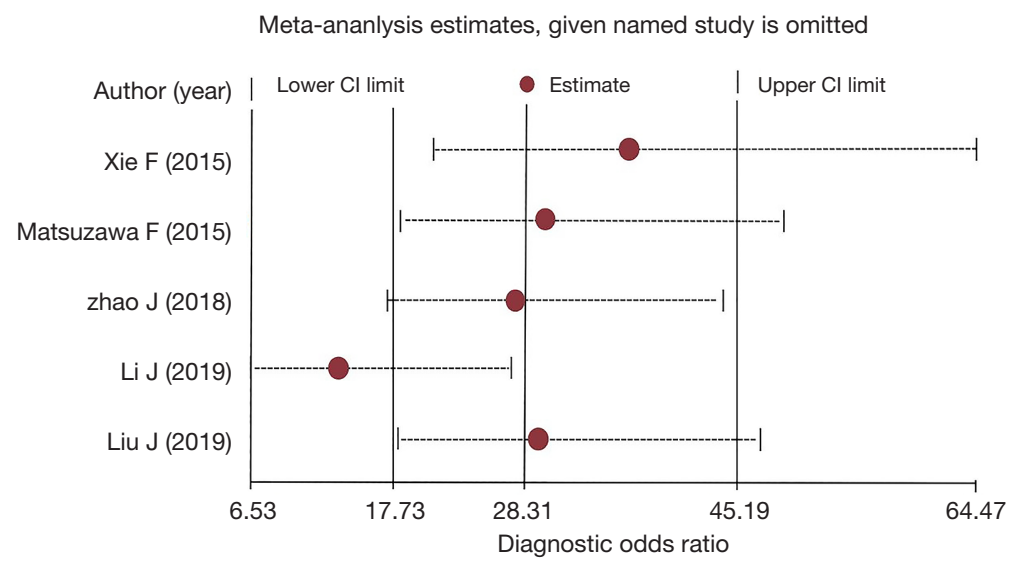

Figure 7 Influence analysis of each study with diagnostic odds ratio estimates and $95 \%$ CIs.

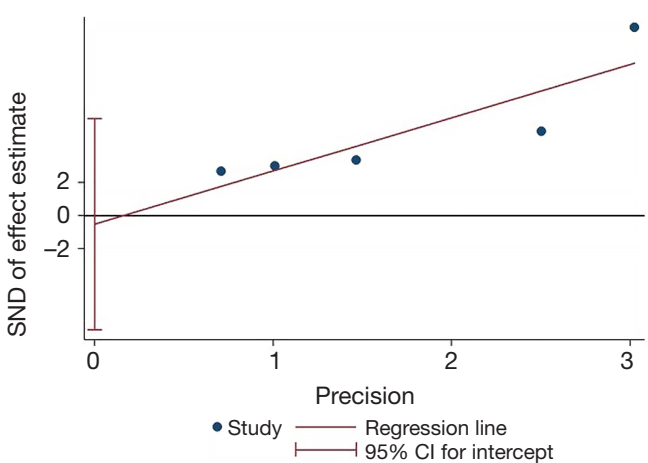

Figure 8 Egger's regression test to estimate publication bias.

only patients with negative palpation were included (19-21). In addition, due to it being a relatively new application in SLN, there was no unified definition of CEUS enhancement patterns in different studies. For example, weak enhancement was defined as a kind of pattern II in the studies of both Zhao and Li. In contrast, this enhancement pattern was considered as a separate pattern, together with a nonenhancement, as pattern III, and was considered as indicating malignant SLNs in the studies of both Liu and Xie, which may have caused the variability in the ratios $(11,21)$. Interobserver heterogeneity may have also contributed to the variability.

Currently, SLN biopsy remains the gold standard to determine the choice of axillary lymph node dissection (7), although preoperative imaging may preclude the need for axillary surgery in a subgroup of patients with early disease and nonpalpable axillary LNs. Several ongoing clinical trials, including the SOUND (Sentinel Node versus Observation after Axillary Ultrasound) (39) and INSEMA (IntergroupSentinel-Mamma) (40) trials, are exploring whether further axillary intervention or SLN biopsy is not required for patients with a negative axillary US examination in earlystage breast cancer. In this meta-analysis, a homogeneous enhancement pattern was highly suggestive of benign lymph nodes with a higher sensitivity of 0.96 , implying CEUS enhancement patterns would be helpful to select patients who do not require axillary surgery. A further prospective trial is necessary to evaluate the value of CEUS and determine whether SLN biopsy might be avoided in a subgroup of patients with a homogeneous CEUS pattern in the SLN.

SLN histopathological evaluation remains the gold standard in determining the precise number of metastatic axillary lymph node dissections, and the assessment of preoperative axillary lymph node burden has drawn great attention recently. According to Zhao, among 87 T1-2 breast cancer patients with a normal axillary US, $100 \%$ of patients $(27 / 27)$ with homogeneous enhancement patterns did not have SLN metastasis, $92.5 \%$ of patients with heterogeneous enhancement patterns had 0-2 SLN metastasis, and $7.5 \%$ had $\geq 3$ SLN metastasis. In addition, all of the patients with no enhancement patterns had SLN involvement, with $57.1 \%$ (4/7) having $\geq 3$ SLN metastasis and $42.9 \%(3 / 7)$ having $1-2$ SLN metastasis. A higher tumor burden is indicated when a nonenhancement pattern is seen pre-operatively. Unfortunately, the diagnostic value of CEUS for the tumor burden of SLNs $(\geq 3$ or $<2$ ) could not be analyzed in this meta-analysis due to the limited data. A more detailed division of enhancement patterns is needed in the future, and further prospective studies 
evaluating the value of CEUS for SLN involvement in assisting preoperative axillary staging are required.

This study had some limitations. First, we mainly studied the diagnostic value of CEUS for SLNs without comparing it with other standard axillary imaging. As a new method, CEUS can identify and assess SLNs simultaneously and expand the field of traditional imaging for SLN diagnosis, which is not applicable for conventional imaging methods. Further large-scale prospective studies are needed to compare its potential diagnostic value for the status of axillary lymph nodes. Second, our meta-analysis was performed based on a small number of studies with obvious heterogeneity, which could affect the meta-analysis. Although the HSROC model and sub-groups analysis were performed, the conclusion should be interpreted with caution.

\section{Conclusions}

This meta-analysis shows that CEUS, as a non-radiation imaging method, can effectively identify the SLN status and further diagnose SLN preoperatively through CEUS enhancement patterns. The appearance of a homogeneous pattern might help determine disease-free axilla and provide information for axillary triage management. Available studies about CEUS enhanced patterns for SLN status diagnosis were small and varied greatly, and their value for lymph node staging is under exploration. Higher-quality studies about CEUS for preoperative lymph node staging are needed.

\section{Acknowledgments}

Funding: This work was supported by the National Natural Sciences Foundation of China (81771855) and CAMS Innovation Fund for Medical Sciences (2017-I2M-1-006).

\section{Footnote}

Reporting Checklist: The authors have completed the PRISMA reporting checklist. Available at https://dx.doi. org/10.21037/qims-21-416

Conflicts of Interest: All authors have completed the ICMJE uniform disclosure form (available at https://dx.doi. org/10.21037/qims-21-416). The authors have no conflicts of interest to declare.
Ethical Statement: The authors are accountable for all aspects of the work in ensuring that questions related to the accuracy or integrity of any part of the work are appropriately investigated and resolved.

Open Access Statement: This is an Open Access article distributed in accordance with the Creative Commons Attribution-NonCommercial-NoDerivs 4.0 International License (CC BY-NC-ND 4.0), which permits the noncommercial replication and distribution of the article with the strict proviso that no changes or edits are made and the original work is properly cited (including links to both the formal publication through the relevant DOI and the license). See: https://creativecommons.org/licenses/by-nc-nd/4.0/.

\section{References}

1. Fisher B, Bauer M, Wickerham DL, Redmond CK, Fisher ER, Cruz AB, Foster R, Gardner B, Lerner H, Margolese R. Relation of number of positive axillary nodes to the prognosis of patients with primary breast cancer. An NSABP update. Cancer 1983;52:1551-7.

2. Beenken SW, Urist MM, Zhang Y, Desmond R, Krontiras $\mathrm{H}$, Medina H, Bland KI. Axillary lymph node status, but not tumor size, predicts locoregional recurrence and overall survival after mastectomy for breast cancer. Ann Surg 2003;237:732-8; discussion 738-9.

3. Giuliano AE, Hunt KK, Ballman KV, Beitsch PD, Whitworth PW, Blumencranz PW, Leitch AM, Saha S, McCall LM, Morrow M. Axillary dissection vs no axillary dissection in women with invasive breast cancer and sentinel node metastasis: a randomized clinical trial. JAMA 2011;305:569-75.

4. Giuliano AE, Ballman KV, McCall L, Beitsch PD, Brennan MB, Kelemen PR, Ollila DW, Hansen NM, Whitworth PW, Blumencranz PW, Leitch AM, Saha S, Hunt KK, Morrow M. Effect of Axillary Dissection vs No Axillary Dissection on 10-Year Overall Survival Among Women With Invasive Breast Cancer and Sentinel Node Metastasis: The ACOSOG Z0011 (Alliance) Randomized Clinical Trial. JAMA 2017;318:918-26.

5. Choi HY, Park M, Seo M, Song E, Shin SY, Sohn YM. Preoperative Axillary Lymph Node Evaluation in Breast Cancer: Current Issues and Literature Review. Ultrasound Q 2017;33:6-14.

6. Chang JM, Leung JWT, Moy L, Ha SM, Moon WK. Axillary Nodal Evaluation in Breast Cancer: State of the 
Art. Radiology 2020;295:500-15.

7. Albertini JJ, Lyman GH, Cox C, Yeatman T, Balducci L, Ku N, Shivers S, Berman C, Wells K, Rapaport D, Shons A, Horton J, Greenberg H, Nicosia S, Clark R, Cantor A, Reintgen DS. Lymphatic mapping and sentinel node biopsy in the patient with breast cancer. JAMA 1996;276:1818-22.

8. Gkegkes ID, Iavazzo C. Contrast Enhanced Ultrasound (CEU) Using Microbubbles for Sentinel Lymph Node Biopsy in Breast Cancer: a Systematic Review. Acta Chir Belg 2015;115:212-8.

9. Mattrey RF, Kono Y, Baker K, Peterson T. Sentinel lymph node imaging with microbubble ultrasound contrast material. Acad Radiol 2002;9 Suppl 1:S231-5.

10. Sever A, Broillet A, Schneider M, Cox K, Jones S, Weeks J, Mills P, Fish D, Jones P. Dynamic visualization of lymphatic channels and sentinel lymph nodes using intradermal microbubbles and contrast-enhanced ultrasound in a swine model and patients with breast cancer. J Ultrasound Med 2010;29:1699-704.

11. Xie F, Zhang D, Cheng L, Yu L, Yang L, Tong F, Liu H, Wang S, Wang S. Intradermal microbubbles and contrastenhanced ultrasound (CEUS) is a feasible approach for sentinel lymph node identification in early-stage breast cancer. World J Surg Oncol 2015;13:319.

12. Sever AR, Mills P, Jones SE, Mali W, Jones PA. Sentinel node identification using microbubbles and contrastenhanced ultrasonography. Clin Radiol 2012;67:687-94.

13. Sever A, Jones S, Cox K, Weeks J, Mills P, Jones P. Preoperative localization of sentinel lymph nodes using intradermal microbubbles and contrast-enhanced ultrasonography in patients with breast cancer. Br J Surg 2009;96:1295-9.

14. Sever AR, Mills P, Jones SE, Cox K, Weeks J, Fish D, Jones PA. Preoperative sentinel node identification with ultrasound using microbubbles in patients with breast cancer. AJR Am J Roentgenol 2011;196:251-6.

15. Esfehani MH, Yazdankhah-Kenari A, Omranipour R, Mahmoudzadeh HA, Shahriaran S, Zafarghandi MR, Amoli HA. Validation of Contrast Enhanced Ultrasound Technique to Wire Localization of Sentinel Lymph Node in Patients with Early Breast Cancer. Indian J Surg Oncol 2015;6:370-3.

16. Nielsen Moody A, Bull J, Culpan AM, Munyombwe T, Sharma N, Whitaker M, Wolstenhulme S. Preoperative sentinel lymph node identification, biopsy and localisation using contrast enhanced ultrasound (CEUS) in patients with breast cancer: a systematic review and meta-analysis.
Clin Radiol 2017;72:959-71.

17. Cox K, Sever A, Jones S, Weeks J, Mills P, Devalia H, Fish $\mathrm{D}$, Jones P. Validation of a technique using microbubbles and contrast enhanced ultrasound (CEUS) to biopsy sentinel lymph nodes (SLN) in pre-operative breast cancer patients with a normal grey-scale axillary ultrasound. Eur J Surg Oncol 2013;39:760-5.

18. Matsuzawa F, Einama T, Abe H, Suzuki T, Hamaguchi J, Kaga T, Sato M, Oomura M, Takata Y, Fujibe A, Takeda C, Tamura E, Taketomi A, Kyuno K. Accurate diagnosis of axillary lymph node metastasis using contrastenhanced ultrasonography with Sonazoid. Mol Clin Oncol 2015;3:299-302.

19. Zhao J, Zhang J, Zhu QL, Jiang YX, Sun Q, Zhou YD, Wang MQ, Meng ZL, Mao XX. The value of contrastenhanced ultrasound for sentinel lymph node identification and characterisation in pre-operative breast cancer patients: A prospective study. Eur Radiol 2018;28:1654-61.

20. Li J, Lu M, Cheng X, Hu Z, Li H, Wang H, Jiang J, Li T, Zhang Z, Zhao C, Ma Y, Tan B, Liu J, Yu Y. How Preoperative Sentinel Lymph Node Contrast-Enhanced Ultrasound Helps Intra-operative Sentinel Lymph Node Biopsy in Breast Cancer: Initial Experience. Ultrasound Med Biol 2019;45:1865-73.

21. Liu J, Liu X, He J, Gou B, Luo Y, Deng S, Wen H, Zhou L. Percutaneous contrast-enhanced ultrasound for localization and diagnosis of sentinel lymph node in early breast cancer. Sci Rep 2019;9:13545.

22. Zhang YX, Wang XM, Kang S, Li X, Geng J. Contrastenhanced ultrasonography in qualitative diagnosis of sentinel lymph node metastasis in breast cancer: A metaanalysis. J Cancer Res Ther 2015;11:697-703.

23. McInnes MDF, Moher D, Thombs BD, McGrath TA, Bossuyt PM; et al. Preferred Reporting Items for a Systematic Review and Meta-analysis of Diagnostic Test Accuracy Studies: The PRISMA-DTA Statement. JAMA 2018;319:388-96.

24. Whiting PF, Rutjes AW, Westwood ME, Mallett S, Deeks JJ, Reitsma JB, Leeflang MM, Sterne JA, Bossuyt PM; QUADAS-2 Group. QUADAS-2: a revised tool for the quality assessment of diagnostic accuracy studies. Ann Intern Med 2011;155:529-36.

25. Irwig L, Bossuyt P, Glasziou P, Gatsonis C, Lijmer J. Designing studies to ensure that estimates of test accuracy are transferable. BMJ 2002;324:669-71.

26. Raslich MA, Markert RJ, Stutes SA. Selecting and interpreting diagnostic tests. Biochem Med 2007;17:151-61.

27. DerSimonian R, Laird N. Meta-analysis in clinical trials. 
Control Clin Trials 1986;7:177-88.

28. Swets JA. Measuring the accuracy of diagnostic systems. Science 1988;240:1285-93.

29. Higgins JP, Thompson SG. Quantifying heterogeneity in a meta-analysis. Stat Med 2002;21:1539-58.

30. Egger M, Davey Smith G, Schneider M, Minder C. Bias in meta-analysis detected by a simple, graphical test. BMJ 1997;315:629-34.

31. Hu Z, Cheng X, Li J, Jiang J, Jiang Z, Li H, Li T, Zhang Z, Tan B, Lu M. Preliminary study of real-time threedimensional contrast-enhanced ultrasound of sentinel lymph nodes in breast cancer. Eur Radiol 2020;30:1426-35.

32. Alvarez S, Añorbe E, Alcorta P, López F, Alonso I, Cortés J. Role of sonography in the diagnosis of axillary lymph node metastases in breast cancer: a systematic review. AJR Am J Roentgenol 2006;186:1342-8.

33. Zhang Q, Suo J, Chang W, Shi J, Chen M. Dualmodal computer-assisted evaluation of axillary lymph node metastasis in breast cancer patients on both realtime elastography and B-mode ultrasound. Eur J Radiol 2017;95:66-74.

34. Wen X, Yu X, Tian Y, Liu Z, Cheng W, Li H, Kang J, Wei T, Yuan S, Tian J. Quantitative shear wave elastography in primary invasive breast cancers, based on collagen-S100A4 pathology, indicates axillary lymph node metastasis. Quant Imaging Med Surg 2020;10:624-33.

35. Hao Y, Ren G, Yang W, Zheng W, Wu Y, Li W, Li X, Li Y, Guo X. Combination diagnosis with elastography strain ratio and molecular markers effectively improves the diagnosis rate of small breast cancer and lymph node

Cite this article as: Niu Z, Xiao M, Ma L, Qin J, Li W, Zhang J, Zhu Q, Jiang Y. The value of contrast-enhanced ultrasound enhancement patterns for the diagnosis of sentinel lymph node status in breast cancer: systematic review and metaanalysis. Quant Imaging Med Surg 2022;12(2):936-948. doi: 10.21037/qims-21-416 metastasis. Quant Imaging Med Surg 2020;10:678-91.

36. Omoto K, Hozumi Y, Omoto Y, Taniguchi N, Itoh K, Fujii Y, Mizunuma H, Nagai H. Sentinel node detection in breast cancer using contrast-enhanced sonography with $25 \%$ albumin--Initial clinical experience. J Clin Ultrasound 2006;34:317-26.

37. Shimazu K, Miyake T, Tanei T, Naoi Y, Shimoda M, Kagara N, Kim SJ, Noguchi S. Real-Time Visualization of Lymphatic Flow to Sentinel Lymph Nodes by ContrastEnhanced Ultrasonography with Sonazoid in Patients with Breast Cancer. Ultrasound Med Biol 2019;45:2634-40.

38. Shimazu K, Ito T, Uji K, Miyake T, Aono T, Motomura K, Naoi Y, Shimomura A, Shimoda M, Kagara N, Kim SJ, Noguchi S. Identification of sentinel lymph nodes by contrast-enhanced ultrasonography with Sonazoid in patients with breast cancer: a feasibility study in three hospitals. Cancer Med 2017;6:1915-22.

39. Gentilini O, Botteri E, Dadda P, Sangalli C, Boccardo C, Peradze N, Ghisini R, Galimberti V, Veronesi P, Luini A, Cassano E, Viale G, Veronesi U. Physical function of the upper limb after breast cancer surgery. Results from the SOUND (Sentinel node vs. Observation after axillary Ultra-souND) trial. Eur J Surg Oncol 2016;42:685-9.

40. Reimer T, Stachs A, Nekljudova V, Loibl S, Hartmann S, Wolter K, Hildebrandt G, Gerber B. Restricted Axillary Staging in Clinically and Sonographically Node-Negative Early Invasive Breast Cancer (c/iT1-2) in the Context of Breast Conserving Therapy: First Results Following Commencement of the Intergroup-Sentinel-Mamma (INSEMA) Trial. Geburtshilfe Frauenheilkd 2017;77:149-57. 
Supplementary

Table MEDLINE/PubMed, EMBASE, and Cochrane Search Strategy

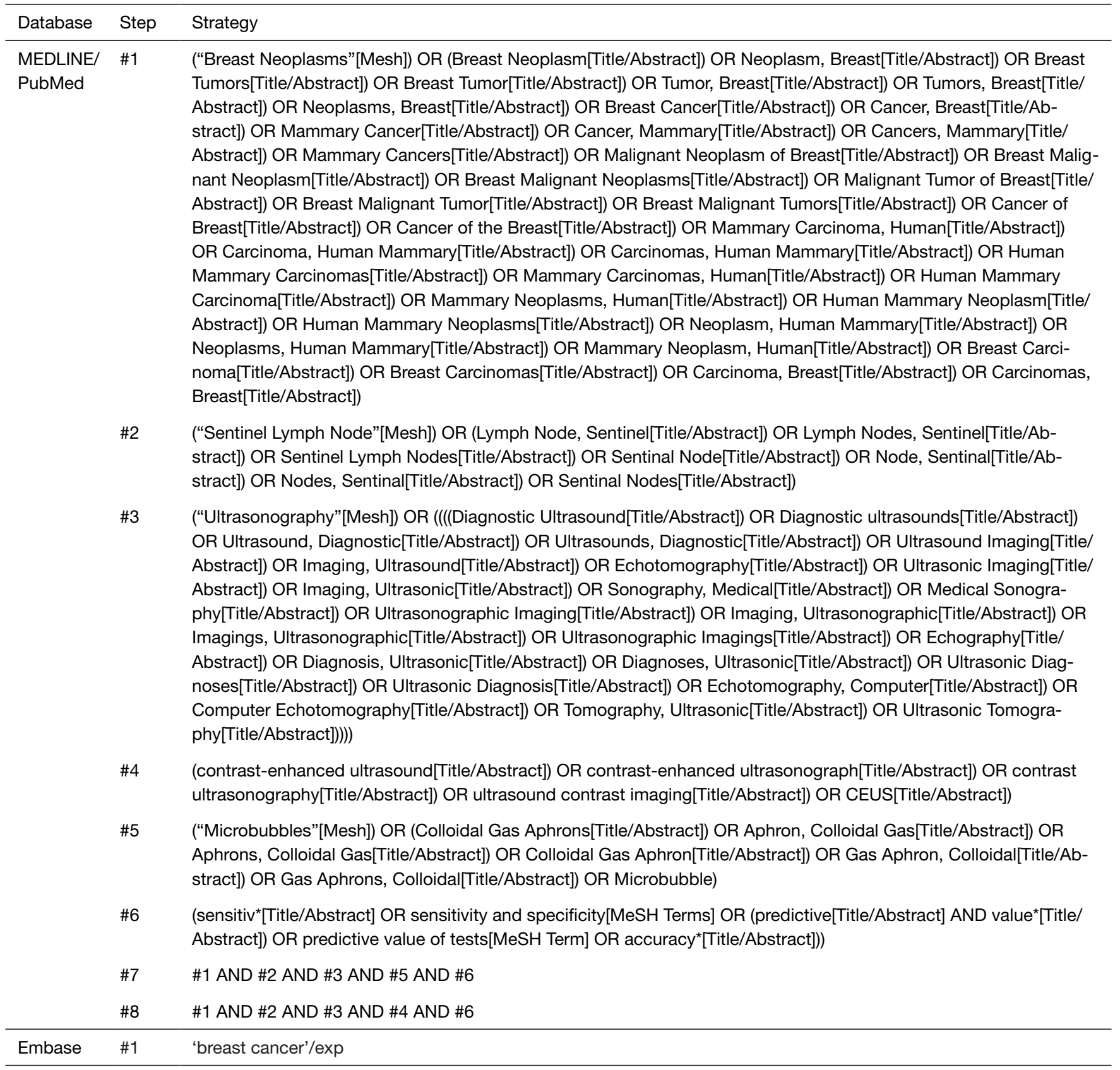

Table (continued) 
Table (continued)

\begin{tabular}{|c|c|c|}
\hline Database & Step & Strategy \\
\hline & \#3 & \#1 OR \#2 \\
\hline & \#6 & \#4 OR \#5 \\
\hline & \#7 & 'contrast-enhanced ultrasound'/exp \\
\hline & \#8 & $\# 3+\# 6+\# 7$ \\
\hline \multirow[t]{7}{*}{ Cochrane } & $\# 1$ & MeSH descriptor: [Breast Neoplasms] explode all trees \\
\hline & \#2 & $\begin{array}{l}\text { (Breast Neoplasm):ti,ab,kw OR (Neoplasm, Breast):ti,ab,kw OR (Breast Tumors):ti,ab,kw OR (Breast Tumor):ti,ab,kw } \\
\text { OR (Tumor, Breast):ti,ab,kw OR (Tumors, Breast):ti,ab,kw OR (Neoplasms, Breast):ti,ab,kw OR (Breast Can- } \\
\text { cer):ti,ab,kw OR (Cancer, Breast):ti,ab,kw OR (Mammary Cancer):ti,ab,kw OR (Cancer, Mammary):ti,ab,kw OR (Can- } \\
\text { cers, Mammary):ti,ab,kw OR (Mammary Cancers):ti,ab,kw OR (Malignant Neoplasm of Breast):ti,ab,kw OR (Breast } \\
\text { Malignant Neoplasm):ti,ab,kw OR (Breast Malignant Neoplasms):ti,ab,kw OR (Malignant Tumor of Breast):ti,ab,kw } \\
\text { OR (Breast Malignant Tumor):ti,ab,kw OR (Breast Malignant Tumors):ti,ab,kw OR (Cancer of Breast):ti,ab,kw OR } \\
\text { (Cancer of the Breast):ti,ab,kw OR (Mammary Carcinoma, Human):ti,ab,kw OR (Carcinoma, Human Mamma- } \\
\text { ry):ti,ab,kw OR (Carcinomas, Human Mammary):ti,ab,kw OR (Human Mammary Carcinomas):ti,ab,kw OR (Mam- } \\
\text { mary Carcinomas, Human):ti,ab,kw OR (Human Mammary Carcinoma):ti,ab,kw OR (Mammary Neoplasms, Hu- } \\
\text { man):ti,ab,kw OR (Human Mammary Neoplasm):ti,ab,kw OR (Human Mammary Neoplasms):ti,ab,kw OR (Neoplasm, } \\
\text { Human Mammary):ti,ab,kw OR (Neoplasms, Human Mammary):ti,ab,kw OR (Mammary Neoplasm, Human):ti,ab,kw } \\
\text { OR (Breast Carcinoma):ti,ab,kw OR (Breast Carcinomas):ti,ab,kw OR (Carcinoma, Breast):ti,ab,kw OR (Carcinomas, } \\
\text { Breast):ti,ab,kw }\end{array}$ \\
\hline & $\# 3$ & \#1 OR \#2 \\
\hline & $\# 4$ & MeSH descriptor: [Sentinel Lymph Node] explode all trees \\
\hline & \#5 & $\begin{array}{l}\text { (lymph nodes, sentinel):ti,ab,kw OR (sentinel lymph nodes):ti,ab,kw OR (sentinal node):ti,ab,kw OR (node, sen- } \\
\text { tinel):ti,ab,kw OR (nodes, sentina):ti,ab,kw OR (sentinal nodes):ti,ab,kw }\end{array}$ \\
\hline & \#6 & \#4 OR \#5 \\
\hline & \#7 & MeSH descriptor: [Ultrasonography] explode all trees \\
\hline
\end{tabular}

Table (continued) 
Table (continued)

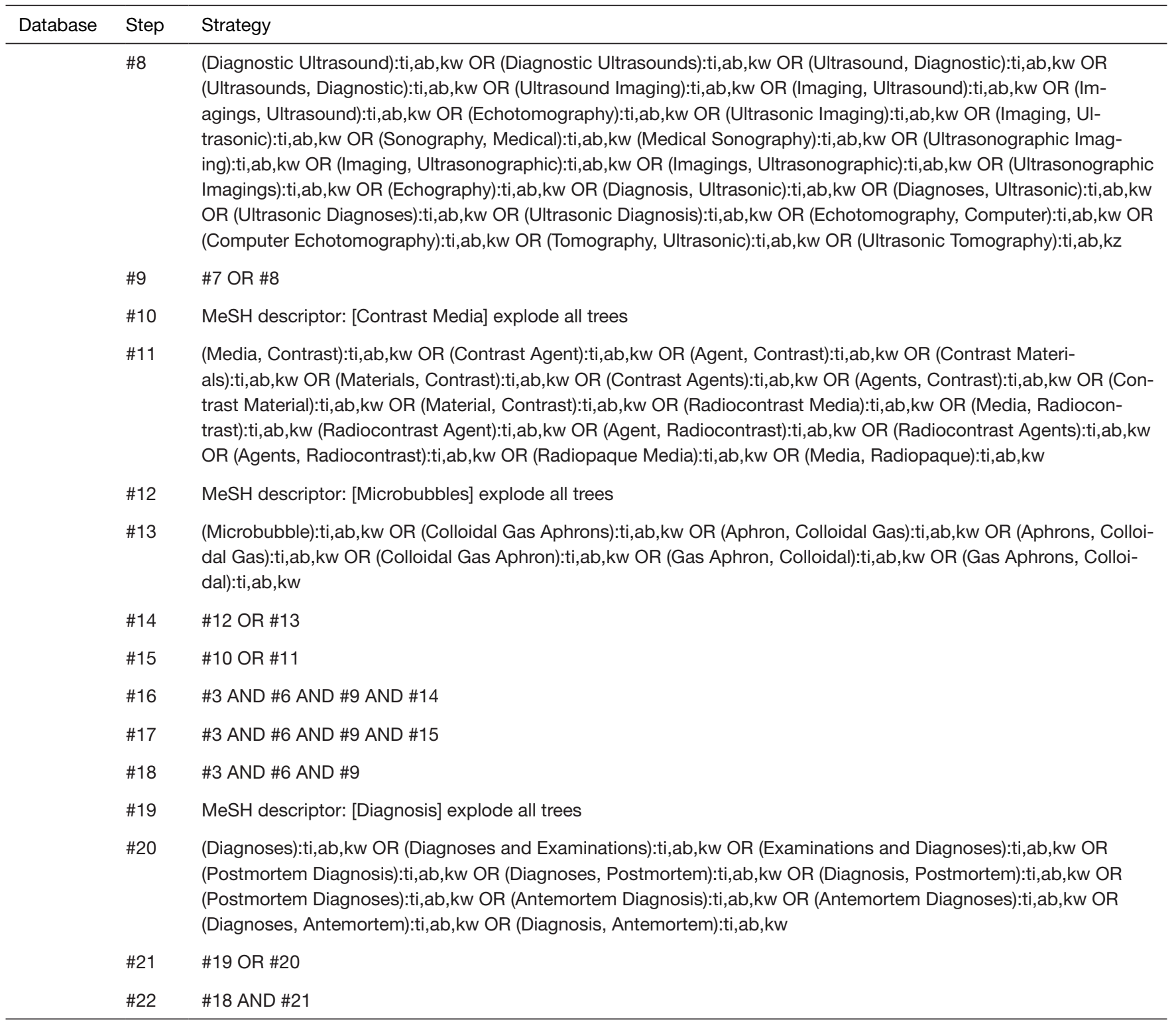

